\title{
Characteristics of Mechanical and Electrical Power Transmission for Small-Scaled Wind Turbine
}

\author{
Kyu-Jin Lee, Hyun-Dai Yang, Sung-Hoon Park, Sung-Do Song, Byung-Sun Kim, Joong-Ho Shin \\ Department of Mechanical Design and Manufacturing, Changwon National University, Changwon-si, South Korea \\ Email: joongho@changwon.ac.kr
}

How to cite this paper: Lee, K.-J., Yang, H.-D., Park, S.-H., Song, S.-D., Kim, B.-S. and Shin, J.-H. (2016) Characteristics of Mechanical and Electrical Power Transmission for Small-Scaled Wind Turbine. World Journal of Engineering and Technology, 4, 82-90.

http://dx.doi.org/10.4236/wjet.2016.43D011

Received: July 15, 2016

Accepted: October 13, 2016

Published: October 20, 2016

\begin{abstract}
Small-scaled wind turbine is converted to mechanical power of windmill to electric power by generator. However almost all studies seems to have overlooked converting relation of mechanical \& electric power. It the reason for was very difficult establishing wind turbine system. In this paper, it is define equation of converting relation of mechanical \& electric power. And it is verified by experimental methods. Defined equation will be used in developing electric devices such as inverter and controller in wind turbines. In addition this method can be used in the fields that utilize the rotational power into electrical power through generator.
\end{abstract}

\section{Keywords}

Wind Turbine, Generator, Mechanical Power, Electrical Power

\section{Introduction}

Recently, there has been a dramatic increase in attention amongst advanced countries paid to environment-friendly energy source due to depletion of fossil energy and environmental issues. Also, there is an urgent need for studies on photovoltaic power generation and wind power generation upon micro grid activation. Particularly, studies on commercialization of small wind power generator are actively conducted as there was an increase in use due to its simple structure, convenient maintenance, and low installation cost.

This paper defines in Equations the relation in which mechanical energy of windmill is converted into electric energy from wind power generator. Also, the accuracy of defined Equations is verified by measuring mechanical power of windmill and electric power of generator when windmill rotates the power generator through gearbox at certain wind speed in simple wind tunnel experiment. 


\section{Composition of Small-Scaled Wind Turbine}

Small wind power generator in this paper was examined for the application to photovoltaic power generation associated hybrid streetlight illustrated in Figure 1. Small wind power generator is composed of windmill and gearbox generator. Vertical windmill (Figure 2) with 12 circular arc shaped wings installed in radial form generates high rotation power even in low wind speed. Gearbox generator illustrated in Figure 3 is in a single unit combined of gearbox and generator to enhance the efficiency by accelerating the low rotations of windmill to high rotations for power generation [1].

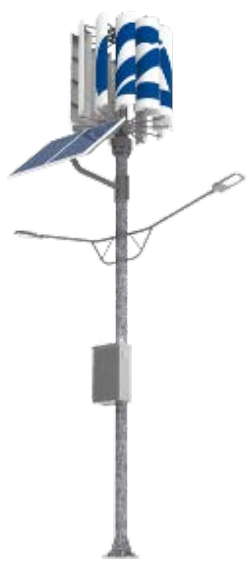

Figure 1. Hybrid streetlamp [2].

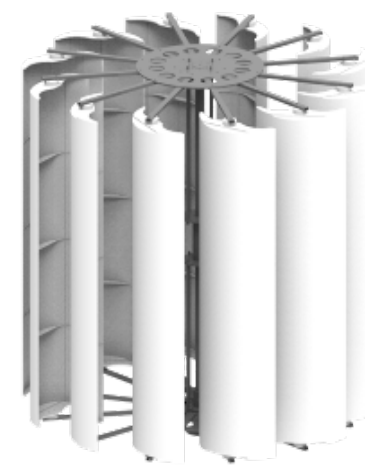

Figure 2. Windmill [2].
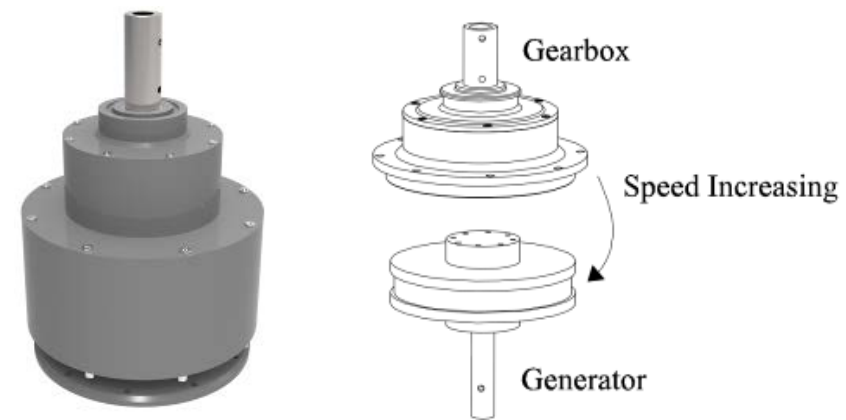

Figure 3. Gearbox generator modeling [2]. 


\section{Mechanical Power of Wind Turbine}

Wind power $P_{W}$ is calculated based on Equations (1) by air density $(\sigma)$, windmill cross-sectional area $(A)$, and wind velocity $(v)$ and mechanical power of windmill $P_{\text {mechanical }}$ can be defined based on Equations (2) by torque $(T)$ and number of rotations $(\omega)$. It is as Equations (3) when number of rotations is converted into RPM.

$$
\begin{gathered}
P_{W}=\frac{1}{2} \sigma A v^{3} \\
P_{\text {mechanical }}=T \cdot \omega \\
P_{\text {mechanical }}=T \cdot R P M \cdot \frac{\pi}{30}
\end{gathered}
$$

\section{Electric Power of Wind Turbine}

Although many parameters do exist as main specification of power generator including voltage, power, RPM (number of rotations), $K_{E}$ (speed constant), $R_{T}$ (resistance), size, weight, temperature, and others, only $K_{E}$ and $R_{T}$ directly associated with electric power have been analyzed.

$V_{F}$ refers to no load voltage and voltage based on rotations of power generator (RPM) are defined as Equations (4).

$$
V_{F}=R P M \cdot K_{E}
$$

Figure 4 is a voltage dip graph to explain $R_{T}$ and the resistance is most directly applied to decrease in power when power generator produces the electricity. Voltage dip phenomenon refers to decrease in actual generating voltage below no load voltage in Equations (4).

Equations (5) illustrates voltage dip $\left(V_{D}\right)$ and generating voltage $\left(V_{G}\right)$ is calculated with Equations (6). In here, Equations (7) illustrates DC power $P_{\text {electric }}$ and it is as Equations (8) when $V_{G}$ is substituted for voltage $V$. Therefore, $R_{T}$ has close relation with electricity production of power generator.

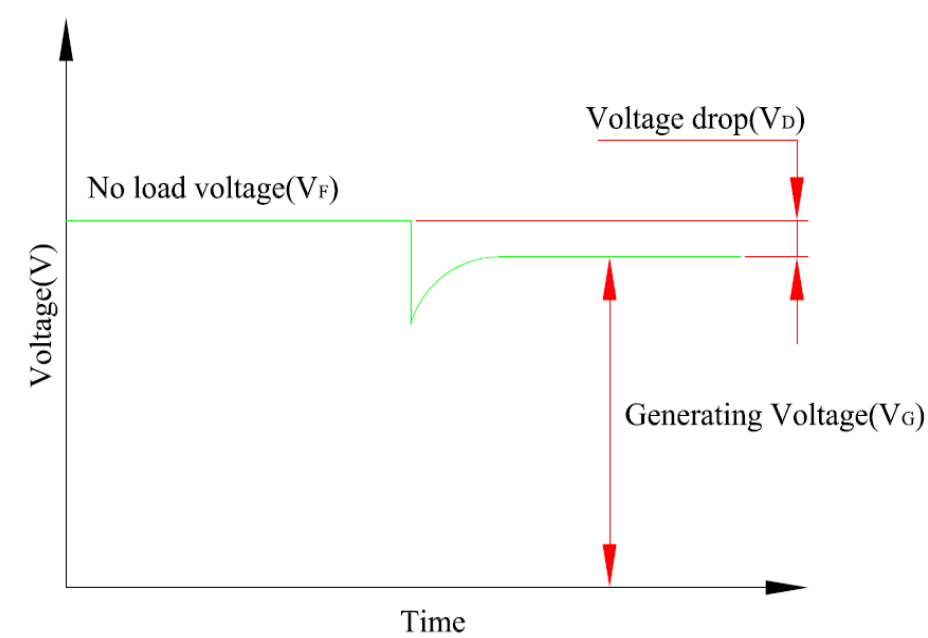

Figure 4. Voltage drop [3]. 


$$
\begin{gathered}
V_{D}=I \cdot R_{T} \\
V_{G}=V_{F}-I \cdot R_{T} \\
P_{\text {electric }}=V \cdot I \\
P_{\text {electric }}=\left(V_{F}-I \cdot R_{T}\right) \cdot I
\end{gathered}
$$

When $R_{T}$ becomes 0 , there is no loss by power generator thus it produces ideal electricity $P_{\text {ideal }}$. Therefore, the efficiency of power generator can be defined as Equations (9).

$$
\operatorname{Efficiency}(\%)=\frac{P}{P_{\text {ideal }}} \times 100
$$

\section{Transmission of Mechanical and Electric Power}

Mechanical power is defined as torque and RPM (rotation per minute) of Equations (3) and electric power is defined as current and voltage as Equations (7). Therefore, in order convert mechanical power into electric power, torque shall be converted into current and RPM shall be changed into voltage. The relation between RPM and voltage can be defined with Equations (10) with the use of Equations (4) and Equations (6).

$$
V=R P M \cdot K_{E}-R_{T} \cdot I
$$

However, there is no interaction Equations of torque and current and Equations (10) is also incomplete as current $I$ is included in the expression.

When there is a decrease in $R_{T}$ value in Equations (8) and (9), there is an increase in efficiency of power generator. In here, there is no loss when $R_{T}$ value is 0 . Therefore, Equations (11) can be defined accordingly with conservation of energy principle suggesting generating power is same as mechanical power. Then, the relation between torque and current can be induced as Equations (12).

$$
\begin{gathered}
R P M \cdot K_{E} \cdot I=T \cdot R P M \cdot \frac{\pi}{30} \\
I=\frac{\pi}{30 K_{E}} \cdot T
\end{gathered}
$$

Since current is constant regardless of efficiency based on conservation law of electric charge, electric power $P_{\text {electric }}$ can be defined as Equations (13) with the use of Equations (7), (10), and (12). In this Equations, generating power is calculated by subtracting transmission loss $P_{\text {loss }}$ of electric power from mechanical power without loss and transmission loss is defined as Equations (14).

$$
\begin{gathered}
P_{\text {electric }}=T \cdot R P M \cdot \frac{\pi}{30}-R_{T}\left(\frac{\pi T}{30 K_{E}}\right) \\
P_{\text {loss }}=R_{T}\left(\frac{\pi T}{30 K_{E}}\right)^{2}
\end{gathered}
$$

\section{Composition of Experiment Device}

Vertical wind power generator in this paper is in structure where diameter of windmill 
can be changed accordingly with the placement of wings and power generation is conducted with gearbox generator. Wind power generation experiment device composed of wind power generator and simple wind tunnel is as illustrated in Figure 5 [4].

Mechanical power experiment device can collect data on RPM of windmill and torque at certain wind speed and display mechanical power curve as illustrated in Figure 6. Electric power experiment device can collect data on generating voltage and current at certain wind speed and display electric power curve as Figure 7.

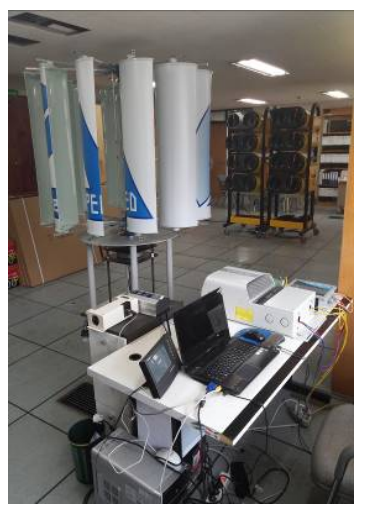

Figure 5. Wind Power system.

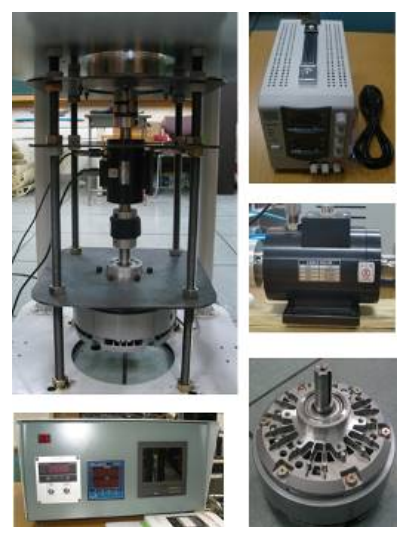

Figure 6. Mechanical measuring systems [3].

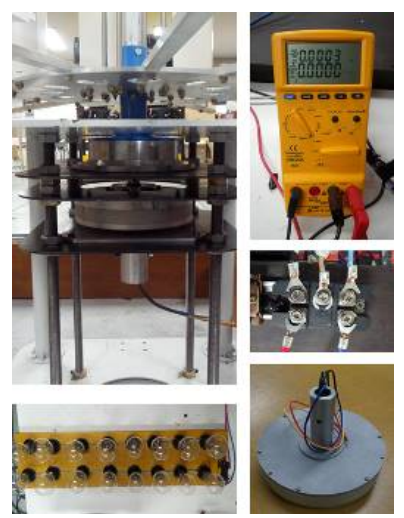

Figure 7. Electric measuring systems [3]. 


\section{Experiment Results}

Mechanical power test and electric power test were conducted with wind power generator applied in this experiment after classification of 4 cases as shown in Table 1 including windmill wing placement at $\Phi 1180$ and $\Phi 1540$ and use of power generator SYG-208-B-100-135 and SYG-208-R-200-300. Electric power curve was induced with interaction Equations using measured mechanical power data and specification of power generator and it was compared with electric power curve displayed through experiment.

Figure 8 compare and display the electric power curve from CASE 1-4 experiment and interaction Equations. Curve induced from experiment was displayed in solid line and curve induced from interaction Equations was displayed in dotted line.

It was verified that highly precise inference can be made from experiment result of Figure 8 and result of Equations (13) proposed in this paper. When illustrating in details the electric power of Case 4 presented in Figure 8(d), Table 2 is experiment result and Table 3 is estimated result by interaction Equations.

\section{Conclusions}

This paper has proposed interaction Equations in which mechanical energy of windmill is converted into electric energy of power generator with the use of wind power theory, power generator theory, conservation of energy principle, conservation law of electric charge and the accuracy was examined through wind tunnel experiment. Reliability was verified as power curve by experiment and inference presented the same trend.

Table 1. Table type styles (Table caption is indispensable).

\begin{tabular}{ccc}
\hline Case & Blade position & Generator \\
\hline CASE 1 & $\Phi 1180$, & SYG-208-B-100-135 $\left(K_{E}=0.29 \mathrm{~V} / \mathrm{RPM}, R_{T}=3.6 \Omega\right)$ \\
CASE 2 & $\Phi 1540$ & SYG-208-B-100-135 $\left(K_{E}=0.29 \mathrm{~V} / \mathrm{RPM}, R_{T}=3.6 \Omega\right)$ \\
CASE 3 & $\Phi 1180$, & SYG-208-R-200-300 $\left(K_{E}=1.134 \mathrm{~V} / \mathrm{RPM}, R_{T}=64 \Omega\right)$ \\
CASE 4 & $\Phi 1540$, & SYG-208-R-200-300 $\left(K_{E}=1.134 \mathrm{~V} / \mathrm{RPM}, R_{T}=64 \Omega\right)$
\end{tabular}

Table 2. Experimental data of CASE 4.

\begin{tabular}{|c|c|c|c|c|c|c|}
\hline & \multirow[t]{2}{*}{ Voltage (V) } & \multirow[t]{2}{*}{ Current (A) } & \multirow[t]{2}{*}{ Max. Power (W) } & \multicolumn{3}{|c|}{$\begin{array}{l}\text { RPM-Power fitting function } \\
\qquad\left(f(x)=a x^{2}+b x+c\right)\end{array}$} \\
\hline & & & & $\mathrm{a}$ & $\mathrm{b}$ & c \\
\hline 1 step & 51.44 & 0.11 & 5.75 & -0.00336 & 0.345636 & -3.13853 \\
\hline 2 step & 58.59 & 0.17 & 10.01 & -0.00467 & 0.546838 & -6.01018 \\
\hline 3 step & 71.43 & 0.24 & 17.08 & -0.00447 & 0.638054 & -5.71139 \\
\hline 4 step & 91.81 & 0.41 & 37.21 & -0.00492 & 0.902811 & -4.23092 \\
\hline 5 step & 105.1 & 0.54 & 56.67 & -0.00578 & 1.214972 & -7.17861 \\
\hline 6 step & 105.77 & 0.55 & 58.46 & -0.00564 & 1.192904 & -4.6289 \\
\hline
\end{tabular}




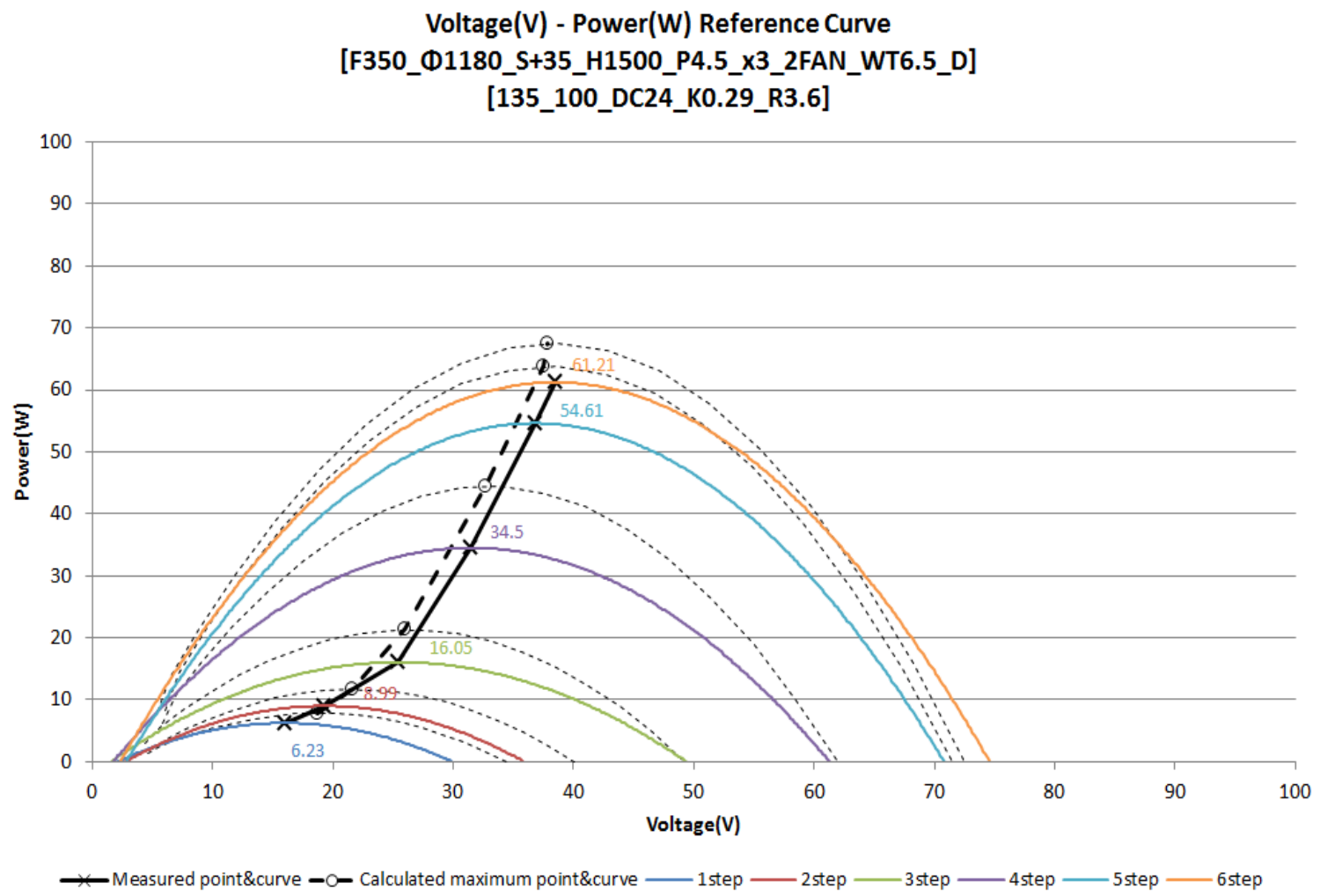

(a)

\section{Voltage(V) - Power(W) Reference Curve \\ [F350_Ф1540_S+35_H1500_P4.5_X3_2FAN_WT6.5_D]}

[135_100_DC24_K0.29_R3.6]

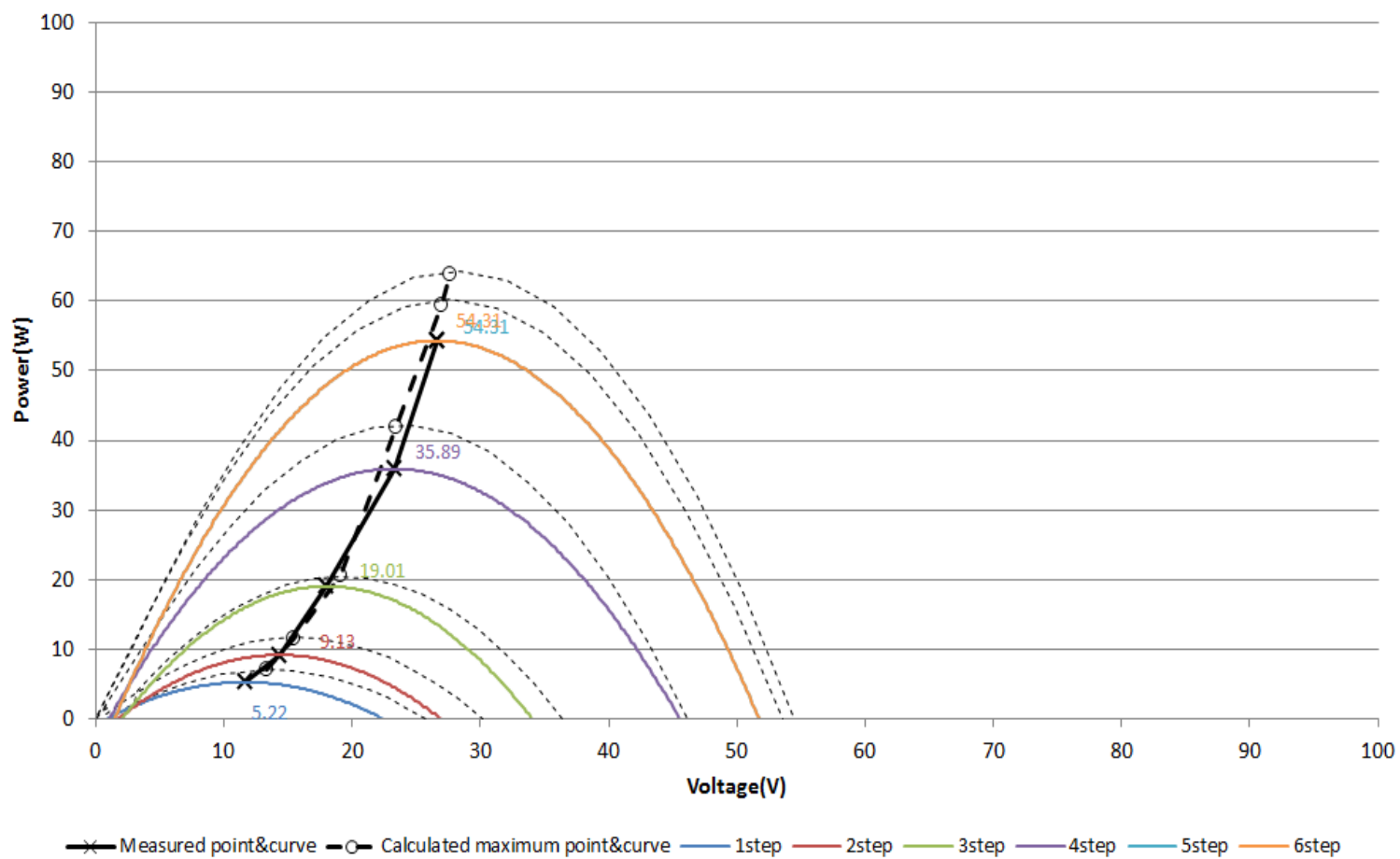

(b) 


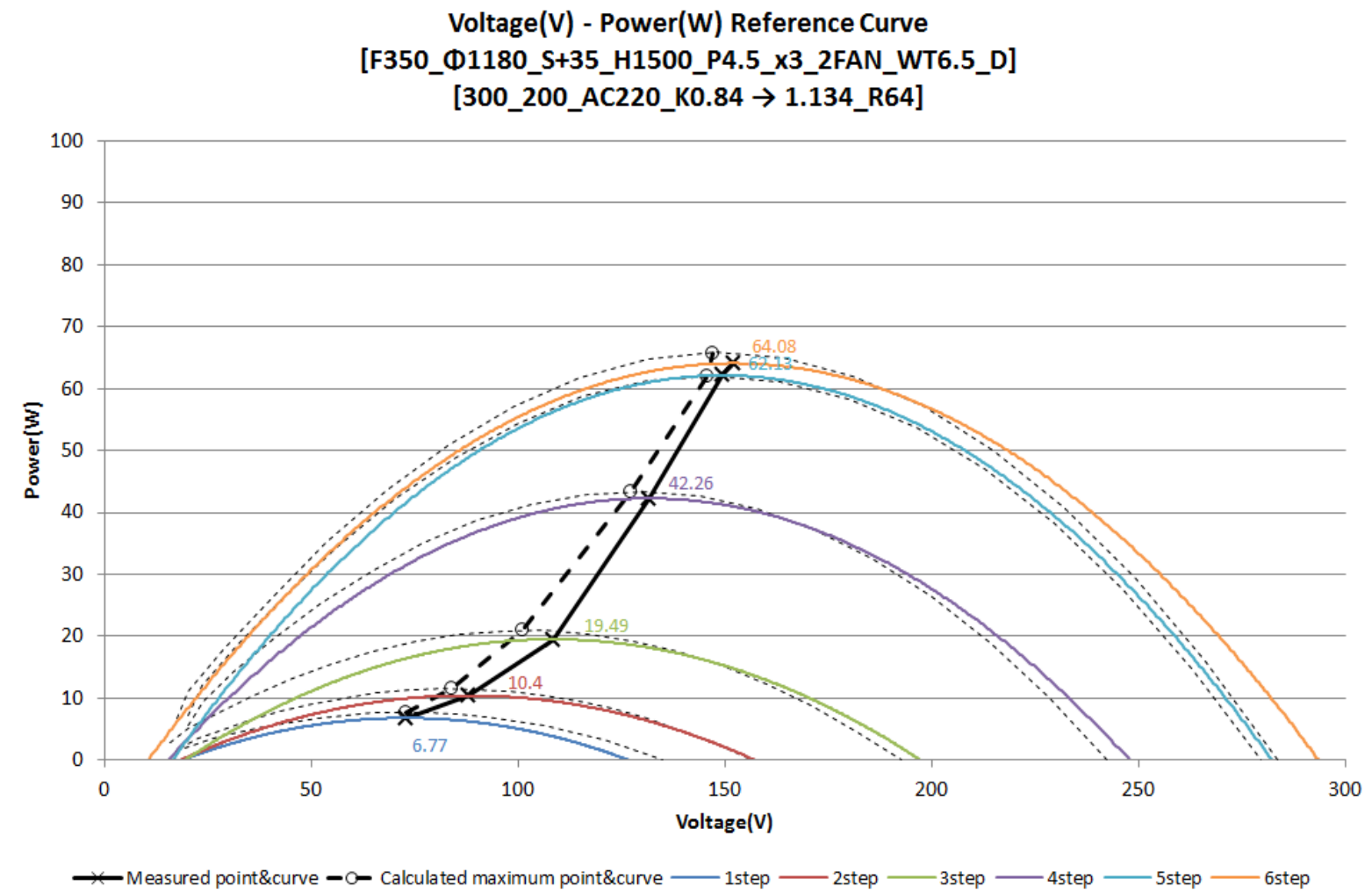

(c)

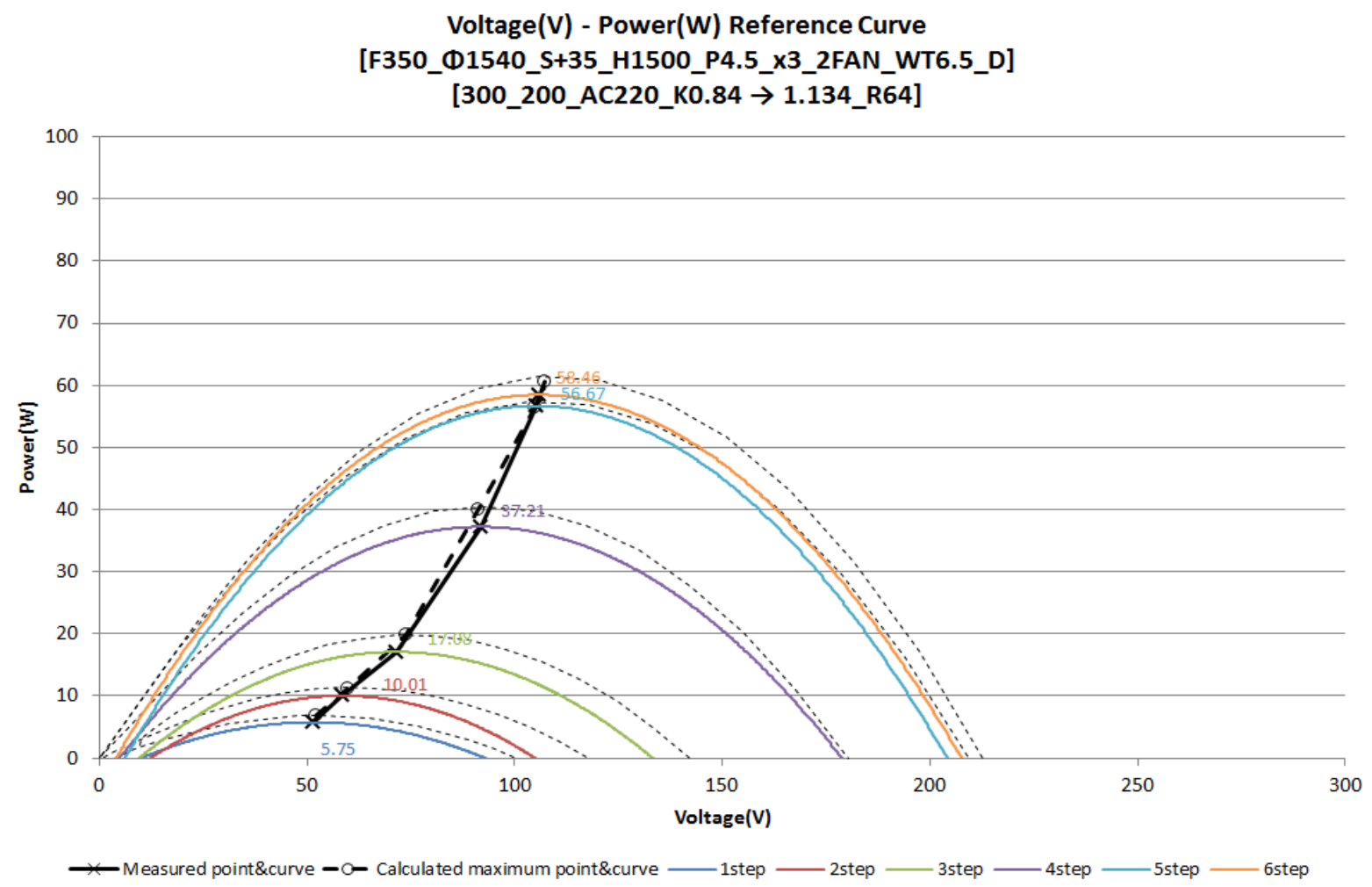

(d)

Figure 8. Power curve. 
Table 3. Equations calculations of CASE 4.

\begin{tabular}{ccccccc}
\hline & & & & \multicolumn{3}{c}{$\begin{array}{c}\text { RPM-Power fitting function } \\
\left(f(x)=a x^{2}+b x+c\right)\end{array}$} \\
& Voltage (V) & Current (A) & Max. Power (W) & \multicolumn{2}{c}{$\mathrm{b}$} & $\mathrm{c}$ \\
\cline { 5 - 7 } & & & & -0.0029 & 0.2974 & -0.9153 \\
\hline 1 step & 52 & 0.13 & 6.82 & -0.0033 & 0.3939 & -0.5269 \\
3 step & 59.83 & 0.19 & 11.26 & -0.0042 & 0.6178 & -2.9899 \\
4 step & 73.87 & 0.27 & 19.83 & -0.0049 & 0.8911 & -0.5184 \\
5 step & 91.06 & 0.44 & 40.05 & -0.005 & 1.0433 & 1.8251 \\
6 step & 104.8 & 0.54 & 56.49 & -0.0053 & 1.1329 & -0.0287 \\
\hline
\end{tabular}

Defined interaction Equations can stipulate the transmission relation of mechanical and electric system. Therefore, it can not only estimate power generating traits for the development of small wind power generation system but also be utilized for development of inverter or controller. Also, it could be applicable for all sectors in which rotation energy is converted into electric energy such as small hydraulic or tidal power generation.

\section{Acknowledgements}

This research was financially supported by Changwon National University in 2016, Korea.

\section{References}

[1] Yang, H.D. (2016) A Study on Design and Performance Analyses of a Stand-Alone Wind/ Solar Hybrid Power Generator System. Doctorate Thesis, Changwon National University, Korea.

[2] Speed-Tech, Hybrid Streetlamp Product Date Sheet.

[3] Lee, K.J. (2015) A Study on Characteristics of Electrical and Mechanical Properties for Small-Scaled Wind Turbines. Master's Thesis, Changwon National University, Korea.

[4] Song, S.D. (2015) A Study on Characteristics of Gearbox Generator for Small-Scaled Wind Power Systems. Master's Thesis, Changwon National University, Korea. 
Submit or recommend next manuscript to SCIRP and we will provide best service for you:

Accepting pre-submission inquiries through Email, Facebook, LinkedIn, Twitter, etc. A wide selection of journals (inclusive of 9 subjects, more than 200 journals)

Providing 24-hour high-quality service

User-friendly online submission system

Fair and swift peer-review system

Efficient typesetting and proofreading procedure

Display of the result of downloads and visits, as well as the number of cited articles

Maximum dissemination of your research work

Submit your manuscript at: http://papersubmission.scirp.org/

Orcontactwjet@scirp.org 